\title{
A Proposed Method for Determining Propulsion Coefficient Based on Testing Motor Freighters on Danube Waterway Network
}

\author{
R. Rajković1 ${ }^{\text {, D. Mitić }}$ 2 $^{*}$, A. Lebl ${ }^{2}$, S. Rajković ${ }^{3}$ \\ ${ }^{1}$ Faculty of Mechanical Engineering, Inovation center, Kraljice Marije 16, University of \\ Belgrade, 11000 Belgrade, Serbia \\ e-mail: rrajkovic@mas.bg.ac.rs \\ ${ }^{2}$ Institute for Telecommunications and Electronics, IRITEL A.D., Batajnički put 23, 11080 \\ Belgrade, Serbia \\ e-mail:mita@iritel.com, e-mail: lebl@iritel.com \\ 3 Institute for Forestry, Kneza Višeslava 3, 11030 Belgrade, Serbia \\ E-mail: snezana.rajkovic@forest.org.rs \\ *corresponding author
}

\begin{abstract}
The paper presents a proposal of mathematical models for the determination of propulsion coefficient, $\eta p p$, intended for the analysis of motor freighters applied on the river watercourses. As the main paper contribution three different model types are developed, depending on the variable which contributes to $\eta p p$ value. These variables are: 1 . the freighter sailing velocity, $(v)$; 2. the installed capacity of the main drive motor of outboard unit, $\left(N_{\text {inst }}\right)$; 3 . the combination of these two variables, $\left(N_{i n s t}, v\right)$. The models are verified on the examples of several motor freighters which are applied at Danube river. The special attention is paid to the determination of the optimum approximation function in each case. In all three cases it is a quadratic function. The correlation coefficient for the comparison in all analyzed examples is higher than 0.87 , being even higher than 0.99 for the first model.
\end{abstract}

Keywords: Motor freighter, total and friction resistance, residual resistance, propulsion coefficient, correlation coefficient

\section{Introduction}

In the last decades of the twentieth century, the use of motor freighters became increasingly widespread and many ordinary freighters (towing and pushing) were converted into motor freighters (Čolić 2009), fitted with diesel engines of power between $300 \mathrm{~kW}$ and $500 \mathrm{~kW}$, attaining the sailing velocity of $6 \mathrm{~km} / \mathrm{h}$ to $16 \mathrm{~km} / \mathrm{h}$.

Modern motor freighters are equipped with special devices for towing or pushing non-self propelled freighters, which actually makes them boats with linked (combined) properties. When motor freighters are used as tugboats or pushers, their power increases to $600 \mathrm{~kW}$, or more. 
Two opposing approaches can be distinguished in the international use of motor freighter in river traffic. The first one is that adopted by the USA, where motor freighters are not used in river traffic, but the entire traffic is realized by pushing. The other approach is that adopted by the developed countries of Western Europe (Germany, the Netherlands, France and Belgium), where towing is replaced by motor freighters and tankers.

The advantages of motor freighters over towed or pushed convoys are very convincing when the comparison involves motor freighters and towed or pushed convoys of the same total capacity. In these cases, transport by motor freighters is not only better (higher speeds and shorter transport), but also cheaper.

However, this comparison is only appropriate when flows of goods, technical-exploitational characteristics of waterway and other exploitational conditions make such comparison justifiable. Otherwise, when comparing economic advantages of motor freighter to those of pushed convoys, the basis for comparison of the most advantageous technical-exploitational properties of both types of vessels should be established by means of calculation.

This paper presents the mathematical models for determining propulsion coefficient $\eta_{p p}$ : depending on the ship's velocity with respect to water, $v$; depending on the installed capacity of the main drive motor of outboard units, $N_{\text {inst }}$; depending on the capacity of the main drive motor at the ship's velocity of $6 \mathrm{~km} / \mathrm{h}$ to $12 \mathrm{~km} / \mathrm{h}$; and depending both on the installed capacity of the main drive motor of outboard unit and the sailing velocity of the motor freighters 'MT700', 'MT850', 'MT1000', 'MT1500', 'MT1800' and 'MT2600'.

Three mathematical models have been identified by means of application of mathematical correlation: $\eta_{p p}=f(v), \eta_{p p}=f\left(N_{i n s t}\right), \eta_{p p}=f\left(N_{\text {inst }}, v\right)$. The mathematical models enable us to obtain the exact value of the motor freighter's propulsion coefficient: firstly, the sailing velocity with respect to water is known; secondly, if the installed (nominal) power of outboard drives, $N_{\text {inst }}$ for the sailing velocity within the range of $6 \mathrm{~km} / \mathrm{h}$ to $12 \mathrm{~km} / \mathrm{h}$, is known; and, lastly, if $N_{\text {inst }}$ and the sailing velocity with respect to water are known.

\section{Numerical methods for determination the total resistance and coefficient of propulsion}

When sailing (Čolić 2002) in still water of sufficient depth and width, the ship's total resistance (Lompar 2002, MAN 2011, Kristensen 2013, Guldhammer 1974), Ruk, consists of two components: the friction resistance, Rtr and residual resistance, Rost, and can be expressed as:

$$
R_{u k}=R_{t r}+R_{o s t}
$$

This classification was introduced by English engineer William Froude (1988). Based on this classification, the friction resistance and the residual resistance (Froude 1888) will be briefly explained in the following subsections.

\subsection{Friction resistance}

The friction resistance is determined by two methods: the William Froude's method (Froude 1888) and the method ITTC (1957).

\subsubsection{William Froude's method}

Based on a conducted testing, Froude $(1872,1874,1888)$ devised a formula for calculation of the ship's friction resistance:

$$
R_{t r}=f \cdot \rho \cdot S \cdot v^{1.83}
$$


where $\rho$ is the water density, $v$ is the ship's sailing velocity in still water of sufficient depth and width, $f$ is the friction coefficient (for the corresponding surface roughness of wetted ship hull). The value of $f$ can be expressed by the following equation:

$$
f=k \cdot \lambda_{s}
$$

where $\lambda_{s}$ is the friction coefficient of technically smooth surface that depends on the length of ship (Rajković 2010), $k$ is the coefficient that takes into account the roughness of surface of wetted hull and is within the range of 1.05 to $1.20, S$ is the wetted surface of the hull, which is calculated according to the V V Zvonkov's formula (Zvonkov 1957):

$$
S=L_{K V L}\left(m T_{K M}+n \delta B_{K V L}\right)
$$

In the equation (4) $L_{K V L}$ is the length of hull at the construction waterline $(K V L), T_{K M}$ is the ship's largest design draft, $B_{K V L}$ is the width of hull at $K V L, \delta$ is coefficient of fullness of hull displacement, which is derived from the formula:

$$
\delta=\frac{V_{M}}{L_{K V L} \cdot T_{K M} \cdot B_{K V L}}
$$

where $V_{M}$ is the displacement of ship.

The values of coefficients $m$ and $n$ in (4) depend on the type of ship, while for motor freighters their values are $m=1.36, n=1.24$.

\subsubsection{Method ITTC-1957}

The ITTC-1957 procedure for determination of the total ship resistance, $R_{u k}$, is as follows, according to ITTC (1957), Bertram (2000), ITTC (1978). At an international meeting of the testing pool administrations (International Towing Tank Conference ITTC-1957), it was agreed that, instead of the William Froude's equation (2), the following equation can also be used for calculation of frictional resistance:

$$
R_{t r}=\left(\xi_{t}+\xi_{r}\right) \cdot \frac{\rho}{2} \cdot S \cdot v^{2}
$$

where $\zeta_{\gamma}$ is the roughness coefficient (Tab. 1), $\rho$ is the water density, $v$ is the ship's sailing velocity in still water of sufficient depth and width, $S$ is the surface area of hull, $\zeta_{t}$ is the friction coefficient of technically smooth surface. The $\zeta_{t}$ coefficient is determined by the following equation:

$$
\xi_{t}=0.083 \cdot(\log \operatorname{Re}-1.65)^{-2}
$$

where $R e$ is the Reynolds number, which is equal to:

$$
\operatorname{Re}=\frac{v \cdot L_{k v l}}{v}
$$

where: $L_{k v l}$ is the length of ship at KVL, $v$ is the coefficient of kinematic viscosity of water (e.g. at water temperature $\left.\mathrm{t}=16^{\circ} \mathrm{C}, v=1.11 \cdot 10^{-6}\right)$.

\begin{tabular}{|l|l|l|}
\hline Roughness of wetted surface & $\xi_{r}$ & $f$ \\
\hline Fully welded hull, colored smooth & 0.0004 & $1.05 \cdot \lambda_{\mathrm{s}}$ \\
\hline Plating welded ribs connected with rivets, colored smooth & 0.0005 & $1.10 \cdot \lambda_{\mathrm{s}}$ \\
\hline Plating folded in length to fold, colored smooth & 0.0006 & $1.15 \cdot \lambda_{\mathrm{s}}$ \\
\hline Sheeting nailed lengthwise folding, rough coated resin & 0.0007 & $1.20 \cdot \lambda_{\mathrm{s}}$ \\
\hline
\end{tabular}


Table 1. Roughness coefficient

\subsection{Residual resistance}

Out of a large number of equations, the Laboratory for Testing of Ships and Waterways, at the Faculty of Traffic and Transport Engineering, University of Belgrade, applies the following one (Čolić 2010):

$$
R_{o s t}=C_{o} \cdot \frac{\rho}{2} \cdot V_{M}^{\frac{2}{3}} \cdot v^{2}
$$

where $\rho, V_{M}$ and $v$ are as in earlier equations (2), (5), $C_{o}$ is the coefficient of residual resistance. $C_{o}$ depends on the shape of ship's bow and stern, the proportions of hull $\left(L_{k v} / B_{k v l}, L_{p s} / L_{k v l}, T_{k m} / B_{k v l}\right)$, and the coefficient $\delta$. Here, $L_{p s}$ represents the length of parallel mid-hull.

\subsection{V.V. Zvonkov's method for determination of total resistance}

This method, which is used for calculation of total resistance of towed and pushed freighters, as well as self-propelled motor freighters, consists of two parts, (1): the first part is friction resistance, determined by William Froude, and the second part is the residual resistance determined by Zvonkov (1957):

$$
\begin{gathered}
R_{t r}=f \cdot \rho \cdot S \cdot v^{1.83} \\
R_{o s t}=\phi \cdot g \cdot \delta \cdot F_{\otimes} \cdot v^{1.7+0.15 \cdot v} \\
R_{u k}=R_{t r}+R_{o s t}=f \cdot \rho \cdot S \cdot v^{1.83}+\phi \cdot g \cdot \delta \cdot F_{\otimes} \cdot v^{1.7+0.15 \cdot v}
\end{gathered}
$$

where $f, \rho, v$ and $\delta$ are values explained earlier; $\varphi$ is the coefficient of residual resistance, whose value for motor freighters is: $\varphi=3$; $g$ is the gravitational acceleration; $S$ is the wetted hull surface; $F_{\otimes}$ is the surface of submerged midship section,

$$
\beta=\frac{F_{\otimes}}{B_{K V L} \cdot T_{K M}} \Rightarrow F_{\otimes}=\beta \cdot B_{K V L} \cdot T_{K M}
$$

The coefficient of residual resistance, $\varphi$, has the same value for motor freighters and tow freighters, which is understandable, because the ship line and the hull shape of both types of freighters are almost the same (except for the stern tunnel). In Serbia, the coefficient of residual resistance is significantly lower than the one recommended by Zvonkov (1957) for freighters of spoon-shaped designs and cutwaters, since Danube freighters have significantly slimmer lines.

\subsection{Calculation of propulsion coefficient (Kristensen 2013)}

The effective power, $N_{\text {eff }}$, is the power that overcomes the resistance of ship (Lompar 2002; Kreculj 1988) and is equal to:

$$
N_{e f f}=R_{u k} v
$$

where $R_{u k}$ is the ship's total resistance, $v$ is the sailing velocity with respect to water.

The installed power (Lompar 2002) of the main drive motor, $N_{\text {inst }}$ is equal to:

$$
\mathrm{N}_{\text {inst }}=\frac{N_{e f f}}{\eta_{p p}}
$$


The coefficient of propulsion Lompar (2002), $\eta_{p p}$, is equal to:

$$
\eta_{\mathrm{pp}}=\frac{\mathrm{N}_{\mathrm{eff}}}{N_{\text {inst }}}
$$

For motor boats with propellers (river ships), $\eta_{p p} \approx 0.45$, (MAN 2011; Harvald 1983). By substituting the equation (13) with the equation (15), the following is obtained:

$$
\eta_{\mathrm{pp}}=\frac{\mathrm{R}_{\mathrm{uk}} \cdot \mathrm{v}}{N_{\text {inst }}}
$$

\section{Determining propulsion coefficient of motor freighters equipped with outboard drive unit}

The following motor freighters have been analyzed: 'MT700', 'MT850', 'MT1000', 'MT1500', 'MT1800' and 'MT2600'. Calculated are their resistance and $\eta_{p p}$ for the sailing velocity of $6 \mathrm{~km} / \mathrm{h}$ to $16 \mathrm{~km} / \mathrm{h}$ in still water of sufficient width and depth. The obtained values are presented in Fig. 1 and Fig. 2. Each of these calculations is performed separately for each of the above-mentioned motor freighters, at the speed between $6 \mathrm{~km} / \mathrm{h}$ and the freighter's designed speed. The designed speed of the above-mentioned motor freighters is $12 \mathrm{~km} / \mathrm{h}, 13 \mathrm{~km} / \mathrm{h}, 16 \mathrm{~km} / \mathrm{h}, 16 \mathrm{~km} / \mathrm{h}, 15 \mathrm{~km} / \mathrm{h}$ and $14 \mathrm{~km} / \mathrm{h}$, respectively.

\subsection{Calculation of motor freighters' resistance}

The above-mentioned motor freighters and their specific characteristics have been analyzed (Rajković 2010). Fig. 1 presents the total resistance of analyzed motor freighters, calculated according to the William Froude's method (1).

According to the V V Zvonkov's method (10), this resistance represents the sum of the residual resistance and the friction resistance of the analyzed motor freighters (2), within the defined areas of sailing velocity in still water of sufficient depth and width (Rajković 2010).

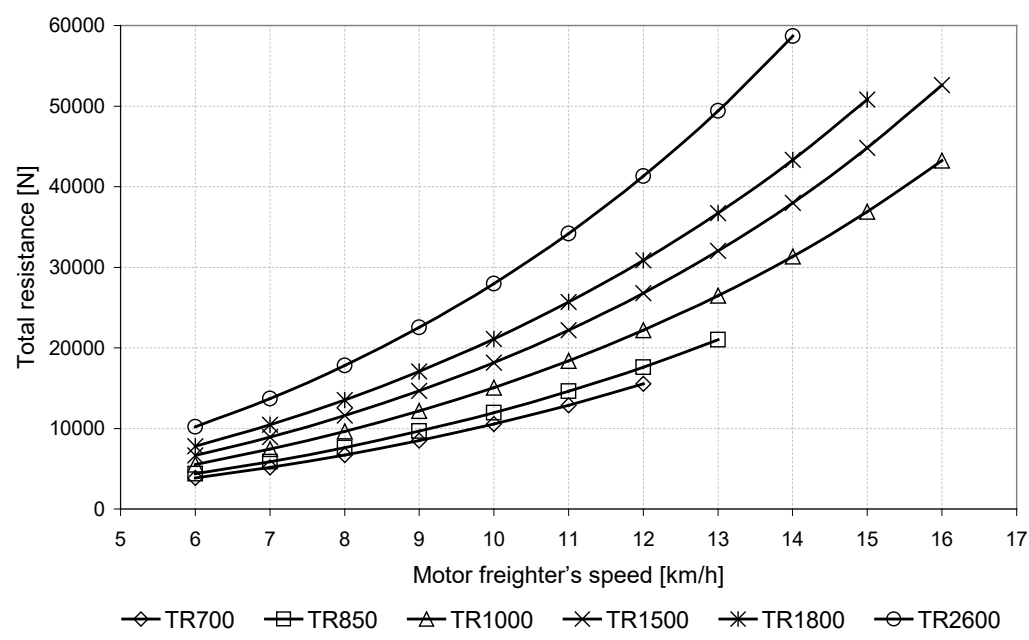

Fig. 1. Graphic representation of the total resistance 


\subsection{Calculation of propulsion coefficient of motor freighters resistance}

The propulsion coefficients (16) of the analyzed motor freighters, with their characteristics (the installed capacity of the main drive motor and the maximum designed speed), are presented in Fig. 2.

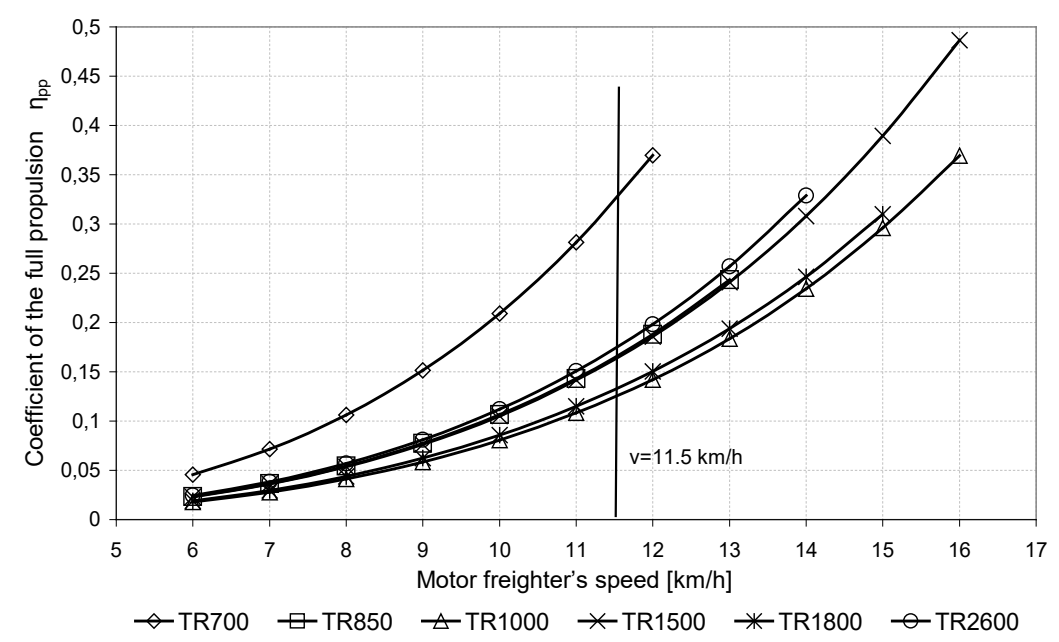

Fig. 2. Graphic representation of the propulsion coefficient, calculated according to the equation (16)

\section{Methods for determining propulsion coefficient based on testing of motor freighters on Danube waterway network}

In our country, great efforts have been put into developing modern methods in the field of technical exploitation of sailing equipment (Čolić 2009) and organization of water transportation (Škiljaica 2010). The examination of technical, exploitational and sailing properties of motor freighters on the Danube waterway network (Radonjić 2007) occupies a special place among these efforts.

This chapter presents the methods (Kalajdžić 2009) and mathematical models for determination of $\eta_{p p}$ depending on: the sailing velocity, the installed capacity of the main drive motor of outboard unit, and the installed capacity of the main drive motor of outboard unit and the sailing velocity. The sailing velocity of the above-mentioned motor freighters was given within the range of $6 \mathrm{~km} / \mathrm{h}$ to $12 \mathrm{~km} / \mathrm{h}$.

\subsection{Mathematical correlation theory}

Establishing a relation between two or more variables requires a collection of different variable values that depend on each other. If $X$ and $Y$ denote sets of data whose relations should be determined, then their pairs of $x_{i} y_{i}$ points can be represented in the coordinate system $O x y$. From the position of $x_{i} y_{i}$ points in the coordinate system, we can visually perceive the shape of the curve, which should be able to approximate the dependence of the variables.

There are several fundamental types of approximate formulae and curves that describe relations between variables. The variable $x$ is declared the independent variable and variable $y$ the dependent, although the converse can also be considered. 
Commonly used approximate curves are:

$$
\begin{aligned}
& \boldsymbol{y}=\boldsymbol{a}_{o}+\boldsymbol{a}_{1} \boldsymbol{x} \quad \text { straight line } \\
& \boldsymbol{y}=\boldsymbol{a}_{o}+\boldsymbol{a}_{1} \boldsymbol{x}+\boldsymbol{a}_{2} \boldsymbol{x}^{2} \quad \text { parabola or quadratic curve } \\
& \boldsymbol{y}=\boldsymbol{a} \boldsymbol{b}^{\boldsymbol{x}} \text { or } \log \boldsymbol{y}=\log \boldsymbol{a}+\boldsymbol{x} \log \boldsymbol{b} \quad \text { exponential curve } \\
& \boldsymbol{y}=\boldsymbol{a} \boldsymbol{x}^{\boldsymbol{b}} \text { or } \log \boldsymbol{y}=\log \boldsymbol{a}+\boldsymbol{b} \log \boldsymbol{x} \quad \text { geometric curve }
\end{aligned}
$$

Approximation of the experimental data can be done simply by observing the distribution of points; however, since various programs determining the approximation and correlation of the curve have appeared in recent years, it is possible to analyze the above-mentioned curves for each set of points. A selection of curve is performed by using the regression or the correlation coefficient. The highest correlation coefficient of a given curve signifies the adoption of the curve for a given set of data.

\subsubsection{Correlation Coefficient}

The basic indicators of data connections are regression equations and correlation coefficients. The regression lines are adjusted for the values of the examined variables. The correlation coefficient indicates the extent to which the actual data dispersion approaches the regression line.

The first orientation in the form of relation between $\mathrm{x}$ and $\mathrm{y}$ is given in the graphical representation of data pairs $(x, y)$ in the coordinate system. The set of points indicating pairs of numbers $x_{i}, y_{i},(i=1,2 \ldots \mathrm{n})$ is called the dispersion diagram or "cloud dispersion". Even on the basis of the points distribution on the graph, the direction and the form of relation characteristic between $x$ and $y$ and, to some extent, the strength of this connection, can be determined. The line, which represents the connection, is called the regression line.

When the dependent variable is estimated by using the regression line, it is also necessary to know how accurate the estimate is. The coefficient of determination and the Pearson correlation coefficient are used as a measure of accuracy of the estimation. The Pearson's correlation coefficient is equal to:

$$
r= \pm \sqrt{\frac{\sum_{i=1}^{n}\left(y_{r}-\bar{y}\right)^{2}}{\sum_{i=1}^{n}\left(y_{i}-\bar{y}\right)^{2}}}= \pm \sqrt{1-\frac{\sum_{i=1}^{n}\left(y_{i}-y_{r}\right)^{2}}{\sum_{i=1}^{n}\left(y_{i}-\bar{y}\right)^{2}}}
$$

The correlation coefficient is a measure of the strength of linear relationship (the dependent variable is estimated by using the regression line) and it takes values in the range between -1 and +1 . When the correlation coefficient approaches unity, it means that the linear relationship between the data pairs $x_{i}, y_{i},(i=1,2 \ldots \mathrm{n})$ is strong, and when the correlation coefficient is close to zero, it means that there is no linear relationship between the data pairs $x_{i}, y_{i},(i=1,2 \ldots \mathrm{n})$. As an empirical rule, the following is accepted:

- the correlation coefficient lower than 0.30 indicates very slight linear relationship between the properties, and its significance is uncertain, especially if the number of data is low;

- the correlation coefficient between 0.50 and 0.70 indicates a significant linear relationship that has a practical importance;

- the correlation coefficient between 0.70 and 0.90 indicates a close relationship;

- the correlation coefficient greater than 0.90 signifies a very close relationship. 


\subsection{Mathematical models for determining propulsion coefficient of motor freighters}

By application of a mathematical model for determination of the motor freighters' propulsion coefficient (Sridhar 2010), a functional relationship between $\eta_{p p}$ and the sailing velocity with respect to water has been established, as well as the relationship between $\eta_{p p}$ and $N_{i n s t}$ for motor freighters for the sailing velocity of $6 \mathrm{~km} / \mathrm{h}$ to $12 \mathrm{~km} / \mathrm{h}$, and the relationship between $\eta_{p p}$ and $N_{\text {inst }}$ and $v$.

Three mathematical models have been identified: $\eta_{p p}=f(v), \eta_{p p}=f\left(N_{\text {inst }}\right), \eta_{p p}=f\left(N_{\text {inst }}, v\right)$.

As can be seen from the presented dependencies, by means of application of this mathematical model, it is possible to obtain the value of the propulsion coefficient of motor freighters if: the sailing velocity with respect to water is known; if the installed capacity of outboard drive for the sailing velocity of $6 \mathrm{~km} / \mathrm{h}$ to $12 \mathrm{~km} / \mathrm{h}$ is known; and if both the installed capacity of outboard drive and the sailing velocity with respect to water are known.

In order to obtain the dependencies $\eta_{p p}=f(v)$ and $\eta_{p p}=f\left(N_{\text {inst }}\right)$, we used Microsoft Office Excel 2003. The coefficients $a_{o}, a_{1}, \ldots, a_{n}$, in the regression equations, and the correlation coefficients $(\boldsymbol{r})$, were obtained by using this program. The results are presented in Tables 2 and 3.

\subsubsection{Mathematical models for determining propulsion coefficient depending on sailing velocity of motor freighters}

The investigation of correlation between $\eta p p$ and the sailing velocity with respect to water, $\eta p p$ $=\mathrm{f}(\mathrm{v})$ has been performed for several types of regression equation (see section 4.1). The results of testing of the regression equation between the propulsion coefficient and the ship's velocity with respect to water, $\eta p p=f(v)$, and their correlation coefficients for the above-mentioned motor freighters, are presented in Table 2.

\begin{tabular}{|c|c|c|c|}
\hline $\begin{array}{l}\text { Motor } \\
\text { freighter }\end{array}$ & Basic equations & Regression equation & $\begin{array}{l}\text { Correlation } \\
\text { coefficients } \\
(\boldsymbol{r})\end{array}$ \\
\hline \multicolumn{4}{|l|}{ MT 700} \\
\hline 1. & $y=a_{o}+a_{I} x$ & $\eta_{\mathrm{pp}}=0.0529 v-0.2986$ & 0.9570 \\
\hline 2. & $\begin{array}{l}y=a_{0}+a_{1} x+a_{2} \\
x^{2}\end{array}$ & $\begin{array}{l}\eta_{p p}=0.0064 v^{2}- \\
0.0629 v+0.1964\end{array}$ & 0.9995 \\
\hline 3. & $y=a b^{x}$ & $\eta_{\mathrm{pp}}=0.0069 \mathrm{e}^{0.3366 v}$ & 0.9947 \\
\hline 4. & $y=a x^{b}$ & $\eta_{\mathrm{pp}}=0.0002 v^{2.9281}$ & 0.9973 \\
\hline \multicolumn{4}{|l|}{ MT850 } \\
\hline 1. & $y=a_{o}+a_{I} x$ & $\eta_{\mathrm{pp}}=0.0308 v-0.1842$ & 0.9578 \\
\hline 2. & $\begin{array}{l}y=a_{o}+a_{1} x+a_{2} \\
x^{2}\end{array}$ & $\begin{array}{l}\eta_{p p}=0.0032 v^{2}- \\
0.0291 v+0.0840\end{array}$ & 0.9979 \\
\hline 3. & $y=a b^{x}$ & $\eta_{\mathrm{pp}}=0.0033 \mathrm{e}^{0.3404 v}$ & 0.9767 \\
\hline 4. & $y=a x^{b}$ & $\eta_{\mathrm{pp}}=0.00008 v^{3.1269}$ & 0.9938 \\
\hline \multicolumn{4}{|l|}{ MT1000 } \\
\hline 1. & $y=a_{o}+a_{1} x$ & $\eta_{\mathrm{pp}}=0.0336 v-0.2282$ & 0.9181 \\
\hline 2. & $\begin{array}{l}y=a_{o}+a_{1} x+a_{2} \\
x^{2}\end{array}$ & $\begin{array}{l}\eta_{\mathrm{pp}}=0.0035 v^{2}- \\
0.0443 v+0.1651\end{array}$ & 0.9975 \\
\hline 3. & $y=a b^{x}$ & $\eta_{p p}=0.0041 \mathrm{e}^{0.2891 v}$ & 0.9923 \\
\hline 4. & $y=a x^{b}$ & $\eta_{\mathrm{pp}}=0.00009 v^{2.9937}$ & 0.9968 \\
\hline \multicolumn{4}{|l|}{ MT1500 } \\
\hline 1. & $y=a_{o}+a_{1} x$ & $\eta_{\mathrm{pp}}=0.0448 v-0.3057$ & 0.9252 \\
\hline
\end{tabular}




\begin{tabular}{|c|c|c|c|}
\hline 2. & $\begin{array}{l}y=a_{0}+a_{1} x+a_{2} \\
x^{2}\end{array}$ & $\begin{array}{l}\eta_{\mathrm{pp}}=0.0045 v^{2}- \\
0.0539 v+0.1923\end{array}$ & 0.9975 \\
\hline 3. & $y=a b^{x}$ & $\eta_{\mathrm{pp}}=0.0045 \mathrm{e}^{0.3029 v}$ & 0.9790 \\
\hline 4. & $y=a x^{b}$ & $\eta_{\mathrm{pp}}=0.00008 v^{3.1578}$ & 0.9969 \\
\hline \multicolumn{4}{|c|}{ MT1800 } \\
\hline 1. & $y=a_{o}+a_{1} x$ & $\eta_{\mathrm{pp}}=0.0315 v-0.2053$ & 0.9313 \\
\hline 2. & $\begin{array}{l}y=a_{0}+a_{1} x+a_{2} \\
x^{2}\end{array}$ & $\begin{array}{l}\eta_{p p}=0.0033 v^{2}- \\
0.0385 v+0.1347\end{array}$ & 0.9982 \\
\hline 3. & $y=a b^{x}$ & $\eta_{\mathrm{pp}}=0.0036 \mathrm{e}^{0.3045 v}$ & 0.9907 \\
\hline 4. & $Y=a x^{b}$ & $\eta_{\mathrm{pp}}=0.00008 v^{3.0322}$ & 0.9966 \\
\hline \multicolumn{4}{|c|}{ MT2600 } \\
\hline 1. & $y=a_{o}+a_{1} x$ & $\eta_{p p}=0.0375 v-0.2361$ & 0.9429 \\
\hline 2. & $\begin{array}{l}y=a_{o}+a_{1} x+a_{2} \\
x^{2}\end{array}$ & $\begin{array}{l}\eta_{p p}=0.0040 v^{2}-0.0428 \\
v+0.1386\end{array}$ & 0.9983 \\
\hline 3. & $y=a b^{x}$ & $\eta_{\mathrm{pp}}=0.0037 \mathrm{e}^{0.3311 v}$ & 0.9770 \\
\hline 4. & $Y=a x^{b}$ & $\eta_{\mathrm{pp}}=0.00007 v^{3.1822}$ & 0.9959 \\
\hline
\end{tabular}

Table 2. Regression equation between $\eta_{p p}$ and $v$ and their correlation coefficients

As can be seen from Table 2, the regression equation under the number 2 (parabola) has the highest correlation coefficient of all analyzed motor freighters $(0.9995,0.9979,0.9975,0.9975$, $0.9982,0.9983$ ), and this equation is adopted as the final solution. If, for example, the 'MT700' motor freighter's sailing velocity with respect to water of $11.5 \mathrm{~km} / \mathrm{h}$ is entered into the equation (using parabolas $\eta_{p p}=f(v)$, the obtained value of propulsion coefficient is 0.31945 , Fig. 3 . By comparison of the calculated value $\eta_{p p}$ (using (16) Fig. 3 (0.31945)), and the value $\eta p p$ determined in Fig. 2 (0.324168), it is concluded that the calculated value has a deviation of $0.471766 \%$ from the graph value, which indicates that the mathematical model is quite well defined.

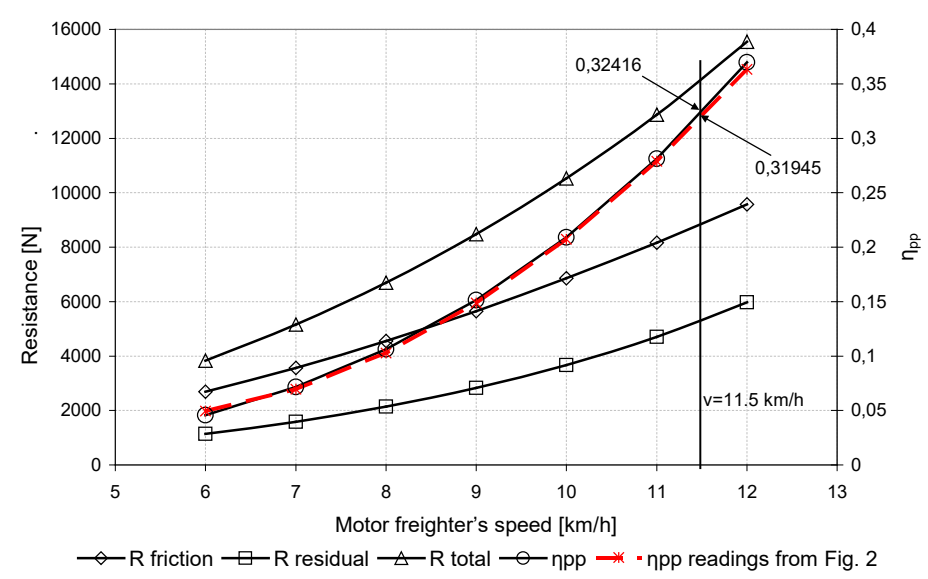

Fig. 3. Graphic representation of the total resistance, friction resistance, residual resistance and the propulsion coefficient: a) calculated according to the equation (16), dashed line, b) readings from Fig. 2, solid line 
4.2.2. Mathematical model for determining $\eta_{p p}$ depending on motor freighter's $N_{\text {inst }}$ for sailing velocity of $6 \mathrm{~km} / \mathrm{h}$ to $12 \mathrm{~km} / \mathrm{h}$

The investigation of correlation between the motor freighters' propulsion coefficient and the installed capacity of outboard drive for the sailing velocity of $6 \mathrm{~km} / \mathrm{h}$ to $12 \mathrm{~km} / \mathrm{h}, \eta_{p p}=f\left(N_{i n s t}\right)$, has been conducted for several types of regression equations (see section 4.1).

The results of the testing of the regression equation between motor freighters' $\eta p p$ and Ninst, $\eta p p$ $=\mathrm{f}(\mathrm{Ninst})$, and their correlation coefficients for the sailing velocity of $6 \mathrm{~km} / \mathrm{h}$ to $12 \mathrm{~km} / \mathrm{h}$, with respect to the above-mentioned motor freighters, are presented in Table 3.

\begin{tabular}{|c|c|c|c|}
\hline $\begin{array}{l}\text { Motor } \\
\text { freighter }\end{array}$ & $\begin{array}{c}\text { Basic } \\
\text { equations }\end{array}$ & Regression equation & $\begin{array}{c}\text { Correlation } \\
\text { coefficients } \\
(\boldsymbol{r})\end{array}$ \\
\hline \multicolumn{4}{|l|}{$\mathrm{v}=6 \mathrm{~km} / \mathrm{h}$} \\
\hline 1. & $Y=a_{o}+a_{1} x$ & $\eta_{\mathrm{pp}}=-0.00004 N_{\text {inst }}+0.0452$ & 0.5680 \\
\hline 2. & $\begin{array}{l}y=a_{0}+a_{1} x+a_{2} \\
x^{2}\end{array}$ & $\begin{array}{l}\eta_{\mathrm{pp}}=2 \cdot 10^{-7} N_{\text {inst }}{ }^{2}- \\
0.0002 N_{\text {inst }}+\mathbf{0 . 0 7 3 5}\end{array}$ & 0.9062 \\
\hline 3. & $y=a b^{x}$ & $\eta_{\mathrm{pp}}=0.0432 \mathrm{e}^{-0.0013 \text { Ninst }}$ & 0.5680 \\
\hline 4. & $y=a x^{b}$ & $\eta_{\mathrm{pp}}=0.604 N_{\text {inst }} t^{-0.5398}$ & 0.7697 \\
\hline \multicolumn{4}{|l|}{$\mathrm{v}=7 \mathrm{~km} / \mathrm{h}$} \\
\hline 1. & $y=a_{o}+a_{1} x$ & $\eta_{\mathrm{pp}}=-0.00005 N_{\text {inst }}+0.0663$ & 0.5869 \\
\hline 2. & $\begin{array}{l}y=a_{0}+a_{1} x+a_{2} \\
x^{2}\end{array}$ & $\begin{array}{l}\eta_{\mathrm{pp}}=2 \cdot 10^{-7} N_{\text {inst }}{ }^{2}- \\
0.0002 N_{\text {inst }}+0.0976\end{array}$ & 0.8726 \\
\hline 3. & $y=a b^{x}$ & $\eta_{\mathrm{pp}}=0.0661 \mathrm{e}^{-0.0011 \text { Ninst }}$ & 0.5577 \\
\hline 4. & $y=a x^{b}$ & $\eta_{\mathrm{pp}}=0.5316 N_{\text {inst }}{ }^{-0.4294}$ & 0.7120 \\
\hline \multicolumn{4}{|l|}{$\mathrm{v}=8 \mathrm{~km} / \mathrm{h}$} \\
\hline 1. & $y=a_{o}+a_{1} x$ & $\eta_{\mathrm{pp}}=-0.00009 N_{\text {inst }}+0.0987$ & 0.4883 \\
\hline 2. & $\begin{array}{l}y=a_{o}+a_{1} x+a_{2} \\
x^{2}\end{array}$ & $\begin{array}{l}\eta_{p p}=5 \cdot 10^{-7} N_{\text {inst }}{ }^{2}- \\
0.0005 N_{\text {inst }}+0.1647\end{array}$ & 0.8855 \\
\hline 3. & $y=a b^{x}$ & $\eta_{\mathrm{pp}}=0.0944 \mathrm{e}^{-0.0012 \text { Ninst }}$ & 0.4433 \\
\hline 4. & $y=a x^{b}$ & $\eta_{\mathrm{pp}}=1.0562 N_{\text {inst }}{ }^{-0.4913}$ & 0.6297 \\
\hline \multicolumn{4}{|l|}{$\mathrm{v}=9 \mathrm{~km} / \mathrm{h}$} \\
\hline 1. & $y=a_{o}+a_{1} x$ & $\eta_{\mathrm{pp}}=-0.0001 N_{\text {inst }}+0.1411$ & 0.5918 \\
\hline 2. & $\begin{array}{l}y=a_{0}+a_{1} x+a_{2} \\
x^{2}\end{array}$ & $\begin{array}{l}\eta_{\mathrm{pp}}=5 \cdot 10^{-7} N_{\text {inst }}{ }^{2}- \\
0.0005 N_{\text {inst }}+0.2129\end{array}$ & 0.8873 \\
\hline 3. & $y=a b^{x}$ & $\eta_{\mathrm{pp}}=0.1402 \mathrm{e}^{-0.0012 \text { Ninst }}$ & 0.5681 \\
\hline 4. & $y=a x^{b}$ & $\eta_{\mathrm{pp}}=1.3741 N_{\text {inst }}{ }^{-0.4701}$ & 0.7290 \\
\hline \multicolumn{4}{|l|}{$\mathrm{v}=10 \mathrm{~km} / \mathrm{h}$} \\
\hline 1. & $y=a_{o}+a_{1} x$ & $\eta_{\mathrm{pp}}=-0.0002 N_{\text {inst }}+0.1948$ & 0.5608 \\
\hline 2. & $\begin{array}{l}y=a_{0}+a_{1} x+a_{2} \\
x^{2}\end{array}$ & $\begin{array}{l}\eta_{\mathrm{pp}}=8 \cdot 10^{-7} N_{\text {inst }}{ }^{2}- \\
0.0008 N_{\text {inst }}+0.3032\end{array}$ & 0.9040 \\
\hline 3. & $y=a b^{x}$ & $\eta_{\mathrm{pp}}=0.1903 \mathrm{e}^{-0.0011 \text { Ninst }}$ & 0.5210 \\
\hline 4. & $y=a x^{b}$ & $\eta_{\mathrm{pp}}=1.7965 N_{\text {inst }}{ }^{-0.4596}$ & 0.7009 \\
\hline \multicolumn{4}{|l|}{$\mathrm{V}=11 \mathrm{~km} / \mathrm{h}$} \\
\hline 1. & $y=a_{o}+a_{1} x$ & $\eta_{\mathrm{pp}}=-0.0002 N_{\text {inst }}+0.2582$ & 0.5517 \\
\hline 2. & $\begin{array}{l}y=a_{0}+a_{1} x+a_{2} \\
x^{2}\end{array}$ & $\begin{array}{l}\eta_{\mathrm{pp}}=10^{-6} N_{\text {inst }}{ }^{2}- \\
0.0011 N_{\text {inst }}+0.4054\end{array}$ & 0.8936 \\
\hline 3. & $y=a b^{x}$ & $\eta_{\mathrm{pp}}=0.2526 \mathrm{e}^{-0.0012 \text { Ninst }}$ & 0.5242 \\
\hline
\end{tabular}




\begin{tabular}{|l|l|l|l|}
\hline 4. & $\boldsymbol{y}=\boldsymbol{a x}^{\boldsymbol{b}}$ & $\eta_{\mathrm{pp}}=2.5395 N_{\text {inst }}{ }^{-0.4728}$ & 0.7022 \\
\hline $\mathrm{v}=12 \mathrm{~km} / \mathrm{h}$ & & & \\
\hline 1. & $\boldsymbol{y}=\boldsymbol{a}_{\boldsymbol{o}}+\boldsymbol{a}_{1} \boldsymbol{x}$ & $\eta_{\mathrm{pp}}=-0.0003 N_{\text {inst }}+0.3414$ & 0.5428 \\
\hline $\mathbf{2 .}$ & $\begin{array}{l}\boldsymbol{y}=\boldsymbol{a}_{\boldsymbol{o}}+\boldsymbol{a}_{1} \boldsymbol{x}+\boldsymbol{a}_{2} \\
\boldsymbol{x}^{\mathbf{2}}\end{array}$ & $\begin{array}{l}\boldsymbol{\eta}_{\mathrm{pp}}=\mathbf{1 0}^{-\mathbf{6}} \boldsymbol{N}_{\text {inst }}{ }^{2}- \\
\mathbf{0 . 0 0 1 5} N_{\text {inst }}+\mathbf{0 . 5 3 7 7}\end{array}$ & $\mathbf{0 . 8 9 3 0}$ \\
\hline 3. & $\boldsymbol{y}=\boldsymbol{a} \boldsymbol{b}^{\boldsymbol{x}}$ & $\eta_{\mathrm{pp}}=0.3332 \mathrm{e}^{-0.0011 ~ N i n s t}$ & 0.5014 \\
\hline 4. & $\boldsymbol{y}=\boldsymbol{a} \boldsymbol{x}^{\boldsymbol{b}}$ & $\eta_{\mathrm{pp}}=3.2451 N_{\text {inst }}{ }^{-0.4657}$ & 0.6786 \\
\hline
\end{tabular}

Table 3. Regression equation between $\eta_{p p}$ and $N_{\text {inst }}$ and their correlation coefficients

As can be seen from Table 3, the regression equation under the number 2 (parabola) has the highest correlation coefficient of all analyzed sailing velocities $(0.9062,0.8726,0.8855,0.8873$, $0.9040,0.8936,0.8930$, respectively), and this equation is adopted as the final solution.

For instance, when analyzing the "Sombor (the name of the ship)" motor freighter, which has the installed capacity of outboard drive unit of $215 \mathrm{~kW}$ (Fig. 4), we obtain the propulsion coefficient for sailing velocities of $6 \mathrm{~km} / \mathrm{h}, 7 \mathrm{~km} / \mathrm{h}, 8 \mathrm{~km} / \mathrm{h}, 9 \mathrm{~km} / \mathrm{h}, 10 \mathrm{~km} / \mathrm{h}, 11 \mathrm{~km} / \mathrm{h}$ and $12 \mathrm{~km} / \mathrm{h}$, in the intersection of the line parallel to the ordinate and the calculated parabolas. By comparing the calculated values (using parabolas $\eta_{p p}=f\left(N_{i n s t}\right)$, for the "Sombor" motor freighter with the values of $\eta_{p p}$ determined in Fig. 4, it can be concluded that the calculated value has a deviation from the value determined in graph, Fig. 5, of between $1.013 \%$ and $3.21 \%$.

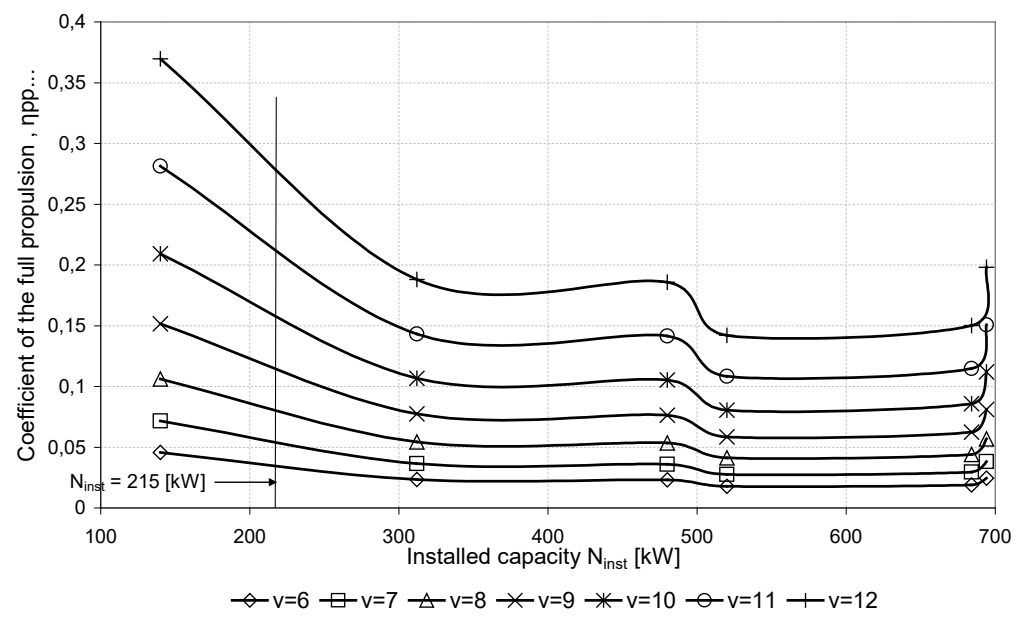

Fig. 4. Propulsion coefficient depending on $N_{\text {inst }}$ for the ship's speed of $6 \mathrm{~km} / \mathrm{h}$ to $12 \mathrm{~km} / \mathrm{h}$ 


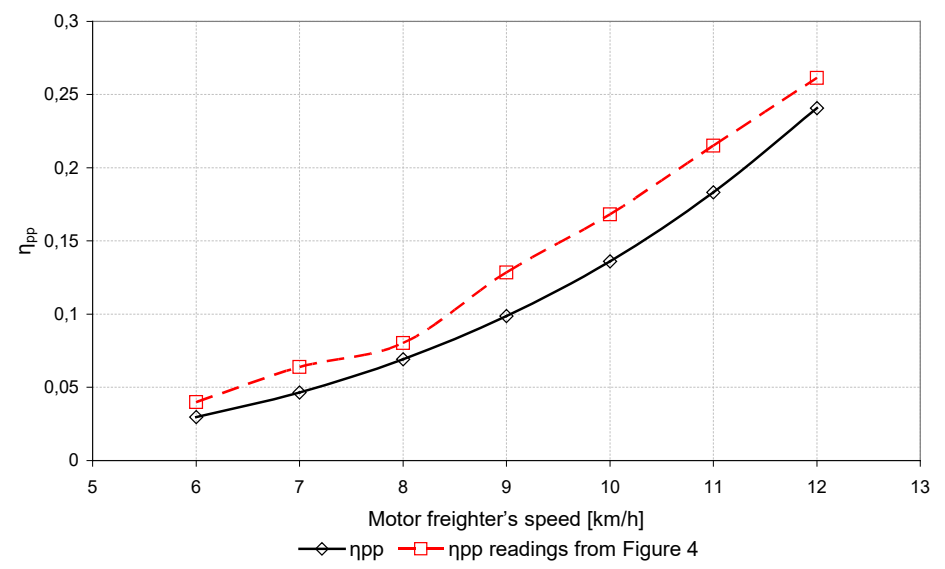

Fig. 5. Comparative overview of the calculated $\eta_{p p}$, solid lines, with the $\eta_{p p}$ values determined in Fig. 4, dashed line

4.2.3. Mathematical model for determining $\eta_{p p}$ depending on $N_{\text {inst }}$ and sailing velocity with respect to water of motor freighters

In order to determine a mathematical model for calculation of the propulsion coefficient depending on the freighter's sailing velocity and the installed capacity of outboard motor, we have firstly designed Fig. 6.

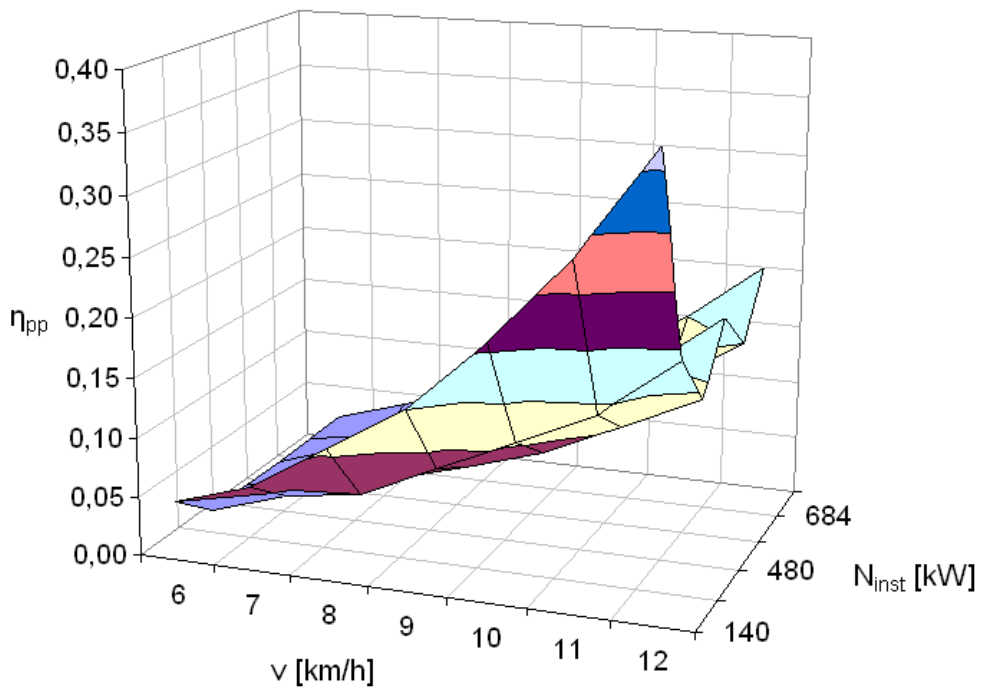

Fig. 6. Dependence of the coeficient $\eta p p$ on Ninst and v, based on the data from Fig. 2

Fig. 6 is formed in a such manner that the motor freighter's sailing velocity is marked on the $x$ axis, the installed capacity of motor freighter's outboard drive is indicated on the $y$-axis, and the $z$-axis denotes the propulsion coefficient corresponding to the installed capacity of motor freighter at a certain speed. The Fig. 6 is obtained by using the velocity of the ship and the installed power of outboard drive with respect to the motor freighter in Fig. 2. In this way, we obtained the 
propulsion coefficient curves depending, first, on the sailing velocity and, second, on the installed capacity of outboard drive of motor freighter, Fig. 6.

Based on the data from Fig. 2, it can be seen that propulsion coefficients of the motor freighters for the speed of $6 \mathrm{~km} / \mathrm{h}$ to $12 \mathrm{~km} / \mathrm{h}$ have the following values:

the 'MT700' from 0.0457 to 0.3697 ;

the 'MT800' from 0.023 to 0.188 ;

the 'MT1000' from 0.017 to 0.142 ;

the 'MT1500' from 0.023 to 0.186 ;

the 'MT1800' from 0.019 to 0.15 ;

the 'MT2600' from 0.024 to 0.198 ;

The propulsion coefficients of motor freighters 'MT1500' and 'MT1800' for the sailing velocity of $6 \mathrm{~km} / \mathrm{h}$ to $12 \mathrm{~km} / \mathrm{h}$ have values that are only slightly different.

'MT1500' and 'MT1800' motor freighters have almost identical propulsion coefficients for all considered sailing velocities.

In order to determine the dependence $\eta_{p p}=f\left(N_{\text {inst }}, v\right)$, a curve of the following form is created:

$$
\eta_{p p}\left(N_{\text {inst }}, v\right)=A \cdot N_{\text {inst }}^{2}-B \cdot N_{\text {inst }}+C \cdot v+D
$$

The parameters A, B, C and D are calculated by using software MATLAB $(\mathrm{C}++)$ and Microsoft Excel (chart), based on a program written in FORTRAN IV, Dock (1972). When the calculated values of parameters are entered, the following equation is obtained:

$$
\eta_{\mathrm{pp}}\left(N_{\text {inst }}, v\right)=1.12 \cdot e^{-6} \cdot N_{\text {inst }}{ }^{2}-1.18 \cdot e^{-3} \cdot N_{\text {inst }}+0.044 \cdot v+0.0473
$$

By using the equation (19), and changing the speed from $6 \mathrm{~km} / \mathrm{h}$ to $12 \mathrm{~km} / \mathrm{h}$ and the installed capacity from $140 \mathrm{~kW}$ to $694 \mathrm{~kW}$, Fig. 7 is obtained.

In order to calculate the coefficient of correlation, it is necessary to determine the sum of squared differences between the measured values and the values obtained by computation and the sum of squared differences between the measured values and the arithmetic mean (the mean value of measurements) obtained by computation. These sums enable calculation of the correlation coefficient according to the equation (17).

When the above-mentioned sums are entered in (17), the obtained value is 0.8613 , which indicates a close relationship between the propulsion coefficient curve obtained by computation, and the propulsion coefficient curve obtained graphically, where propulsion coefficient depends on the sailing speed and the installed power of outboard drive of motor freighters. 


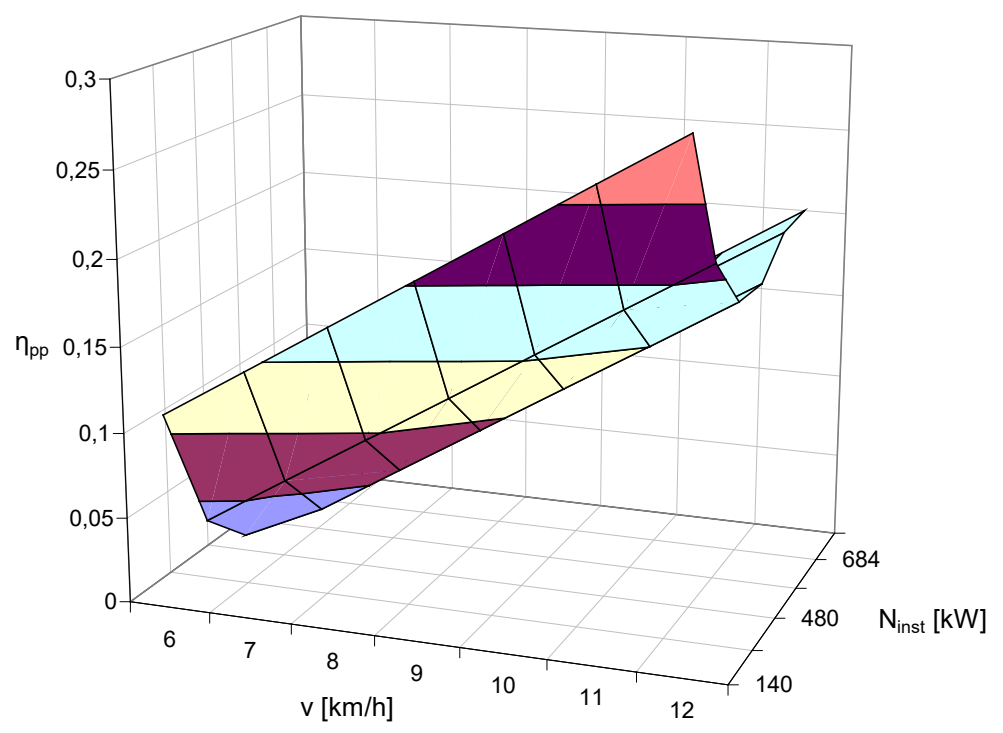

Fig. 7. Determining the dependence of motor freighters' $\eta p p$ on Ninst and v, by use of equation

The 'MT700' motor freighter has the highest deviation of the propulsion coefficient, when comparing the calculated and the values obtained by the mathematical model, while for other motor freighters these differences are insignificant.

\section{Conclusions}

Three mathematical models have been established by application of the mathematical correlation: $\eta_{p p}=f(v), \eta_{p p}=f\left(N_{i n s t}\right), \eta_{p p}=f\left(N_{\text {inst }}, v\right)$. As can be seen from the presented dependencies, it is possible to obtain the value of the motor freighter's propulsion coefficient by application of a mathematical model if: the sailing velocity with respect to water is known; if the installed capacity of outboard drive for the sailing velocity of $6 \mathrm{~km} / \mathrm{h}$ to $12 \mathrm{~km} / \mathrm{h}$ is known; and if the installed capacity of outboard drive and the sailing velocity with respect to water are known.

The regression equation (parabola) has the highest correlation coefficient with respect to the studied motor freighters in the first and in the second model; therefore, this equation is adopted as the final solution. By determining the value of the outboard drive unit's propulsion coefficient by means of application of the first model, the values for the projected sailing velocity between 0.24 and 0.48 were obtained, which are consistent with the values of the experimental study by Colić (2010). In case of the third model, it was not possible to determine the appropriate propulsion coefficients for the projected velocity values, due to a small number of statistical samples or tests.

The analysis of these results has undoubtedly proved the need for a comprehensive sailing and propulsion testing of motor freighters; therefore, efforts must be made to continue this research systematically for all newly-constructed and rebuilt motor freighters, with a view to obtaining a larger number of statistical samples necessary for determining the propulsion coefficient. 
The results of tests, obtained by processing of data, may prove very useful to designers of river ships (especially constructors of propulsion devices), and to professionals involved in technical exploitation of river ships and organization of transportation.

Acknowledgements: The study was carried out within the Project TR - 36027, "Software development and national database for strategic management of the development of means of transport and infrastructure in road, rail, air and water transport by European transport network models", financed by the Ministry of Education, Science and Technological Development, Republic of Serbia.

\section{References}

Bertram V (2000). Practical Ship Hydrodynamics, Butterworth-Heinemann.

Dock V Thomas (1972). FORTRAN IV programming, Reston Pub. Co (1972).

Froude W and Froude RE(1888). The Resistance of Ships, Harvard University.

Froude W (1872). Experiments on the Surface-Friction Experienced by a Plane Moving Through Water, Report of the British Association for the Advancement of Science.

Froude W (1874). Report to the Lords Commissioners of the Admiralty on Experiments for the Determination of the Frictional Resistance of Water on a Surface Under Various Conditions, Report of the British Association for the Advancement of Science.

Guldhammer H.E and Harvald Sv.Aa (1974). Ship Resistance.

Harvald Sv.Aa (1983). Resistance and Propulsion of Ships.

ITTC - Recommended Procedures and Guidelines (1978). ITTC 1978 (performance prediction method).

ITTC - Recommended Procedures and Guidelines (1957). ITTC 1957 (frictional resistance coefficient).

Kalajdžić M and Hofman M (2009). The procedure for calculating the power of the river pushing convoy and computer program CONVOY, Department of Naval Architecture, Mechanical Engineering, University of Belgrade, Report BR002/2009.

Kreculj D and Čolić V(1988). Plovna sredstva, Second edition, Traffic Engineering, University of Belgrade, Belgrade.

Kristensen Hans Otto and Lützen Marie (2013). Prediction of Resistance and Propulsion Power of Ships, Project no. 2010-56, Emissionsbeslutningsstøttesystem Work Package 2, Report no. 04, May 2013.

Lompar A (2002). Science on Ship, University of Montenegro, Kotor, pp.121-159.

MAN Energy Solutions (2011). Basic Principles of Ship Propulsion, MAN Diesel \& Turbo, December 2011.

Rajković R (2010). Determination of Total Propulsion Coefficient for Motor Freighter Equipped with Outboard Drive Unit, Master's Thesis, Traffic Engineering, University of Belgrade, Belgrade.

Radonjić A (2007). Research in Experimental Methods for Determining the Navigable Characteristics of the River Ships, Master's Thesis, Traffic Engineering, University of Belgrade, Belgrade.

Sridhar D Bhanuprakash T.V.K and Das H.N (2010). Frictional Resistance Calculations on a Ship using CFD, International Journal of Computer Applications (0975 - 8887) Vo.11, No.5, December 2010.

Čolić V (2009). Engineering Characteristics of the Navigable Means of Water Transportation, TEHNIKA 646 (2).

Čolić V (2002). Ship Resistance - Modern Methods of Calculation, Traffic Engineering, University of Belgrade, Belgrade, 2002, pp. 1-4. 
Čolić V (2010). Experimental research of technical and exploitation characteristics of selfpropelled passenger and cargo ships on the Danube navigable network, Traffic Engineering, University of Belgrade, Belgrade, 2010.

Škiljaica V Miličić M and Škiljaica I (2010). Technical and Operational Characteristics of Passenger Ships for Urban and Suburban Traffic, TEHNIKA 65, 6 (5).

Zvonkov V V (1957). Principles of Integrated Transport Development in the U.S.S.R. University of Chicago, McBlain Books. 